\title{
Metatheory of Resilience and Resiliency in Adolescent Pregnancy and Substance Use Disorders
}

\author{
Cynthia Carbo and Nancy Goldstein* \\ Johns Hopkins University School of Nursing, USA
}

Submission: August 07, 2018; Published: August 172018

*Corresponding author: Nancy Goldstein, Johns Hopkins University School of Nursing, USA, Email: ngoldst1@jhu.edu

\begin{abstract}
Background: Adolescence is a challenging phase of human development. Characteristics of both the adolescent and environment influence response to life events. Pregnancy is a stressful life event. The pregnant adolescent with substance use disorder (SUD) is not well served by healthcare providers who do not understand the convergence of all three states: adolescence, pregnancy, and SUD.

Objective: Describe a resilience model used as a framework for adaptation in adolescent populations under significant stress during pregnancy and SUDs.

Methods: The authors searched Pub Med, merging the terms "teenage pregnancy", "substance use", and "outcomes". Most addressed risk factors for the pregnant adolescent and fetus in the context of SUD; one addressed behavioral resilience of offspring after intrauterine exposure. This led to a search of resilience theory to find an applicable model in caring for adolescents who may be at risk, pregnant, or may have SUD.

Results: A total of 32 articles were retrieved with 16 matching the criteria search. Resilience involves the ability to grow or adapt to life circumstances. New life circumstances disrupt homeostasis, and require energy to adapt and reintegrate. Interpersonal growth occurs when a person successfully resolves a disruption, but there are more disruptions during adolescence. The newness of these disruptions, with less coping skills and experience, makes adolescence more difficult.

Conclusion: Richardson's model provides a useful, holistic approach to this problem. Fostering resilience involves personal appraisal and improving protective factors for this at- risk population.

Keywords: Adolescent pregnancy; Substance use disorders; Resilience theory; Adaptive response
\end{abstract}

\section{Key Points of Richardson's Metatheory of Resilience}

I. Change and disruption are a part of life and challenge homeostasis

II. Disruptions can move a person out of their comfort zone, causing development of resilient qualities and possible emotional growth.

III. Adaptation equals biopsychospiritual homeostasis.

IV. Achieving homeostasis without leaving ones comfort zone leads to stagnation.

\section{Metatheory of Resilience \& Resiliency in Adolescent Pregnancy and Substance Use Disorders}

Adolescence is one of the most challenging phases of human development. New life circumstances - physical, social and emotional - cause disruptions to one's steady state. There is a greater probability of risk taking behavior and impulsivity [1]. Physical and hormonal changes, life choices, and pressures to succeed and transition to an adult role all challenge homeostasis and can nudge the adolescent out of her comfort zone.
The number and newness of these disruptions make adolescence an exciting time of potential growth, but also a turbulent phase for a person with less judgment, experience and coping skills than most adults. Characteristics of both the adolescent and her environment influence her response to life events. Pregnancy is a stressful life event, even more so in the context of adolescence. Substance use disorder (SUD) can be viewed as both a cause of, and response to, stressors; it can contribute to pregnancy, and present a hazard to mother and baby. The pregnant adolescent with SUD is not well served by healthcare providers who do not understand the confluence of all three states: adolescence, pregnancy and SUD. The authors sought a theoretical construct to guide care of the pregnant adolescent with SUD. It was theorized that this population was under significant stress in all three realms, and that SUD could be a contributing factor to pregnancy. Optimal response to stress benefits both mother and child, and resilience theory contends there is opportunity for growth with life disruptions [2]. The purpose of this article is to propose a guideline for healthcare providers when serving this population. 


\section{Methods}

The Pub med was searched, merging the terms "teenage pregnancy", "substance use", and "outcomes", AND "last 10 years". This yielded 32 articles, 16 of which were relevant. The majority addressed risk factors for the pregnant adolescent and fetus in the context of SUD; one addressed behavioral resilience of offspring after intrauterine exposure. The model from Richardson's metatheory of resilience (2002) provided an understandable and holistic representation of the individual, the environment, and their mutual influences.

\section{Results}

The majority of the literature reviewed listed risk factors for the adolescent or baby, or both. Common themes were found in the literature that focused on the female adolescent. Early substance use interferes with the adolescent's cognitive and social development, and dual use of marijuana and alcohol correlates with the highest rate of teenage pregnancy [3]. In a study from Russia, young women were identified to be at risk who were from a lower educational level, from non-intact families; they preferred stronger drinks, had their sexual debut at an earlier age, and had more frequent sex [4]. Adolescents exposed to heavy doses of cocaine when they were in utero were more likely than those adolescents not exposed to engage in SUD, but high levels of exposure to violence during childhood substantially correlated with substance use initiation [5].

SUD disrupts normal growth and development DeGenna, Cornelius and Donovan [6]. Depression in adolescent mothers is associated with continued use of tobacco and marijuana DeGenna, Cornelius and Donovan [6]. There is risk for the baby additionally. Cumulative contextual risks (low birth weight, adolescent mother, single parent, smoking and alcohol during pregnancy, low socioeconomic status, lack of material resources, multiple unions) cluster in families [7]. Cumulative contextual risk at birth can predict SUD, conduct problems and risky sexual behavior. Prenatal cocaine exposure is thought to affect changes in neural pathways and alter stress response [8]; heightened arousal was noted for girls, and blunted arousal for boys. Future risk included academic problems, violent behavior and unprotected sex. Cocaine use during pregnancy can result in premature labor, cardiac dysrhythmias, and abruptio placenta for the mother, and cardiac anomalies and arrhythmias in the neonate [9]. Prenatal cocaine exposure is also associated with low birth weight, changes in the child's stress response, and decreased executive functioning $[7,10]$.

The literature provides useful information on the effects of smoking, drugs and alcohol during pregnancy [5,6,8,11,12,13].. Maternal tobacco use can lead to low birth weight, increased rates of obesity and hypertension, and attention deficit hyperactivity disorder (ADHD) in the child. Fetal alcohol syndrome and fetal alcohol effects refer to alcohol-related neurodevelopmental disorders in the child; maternal marijuana use can result in neurobehavioral manifestations as well. Maternal cocaine use can potentially cause lasting changes to the developing brain of the fetus [12]: Through the Hypothalamic-pituitary-adrenal (HPA) axis dysregulation that alters the neurochemistry of arousal, attention, and reactivity to stress. Methamphetamine can cause anorexia in the mother, and vasoconstriction that can decrease nutrition and oxygen delivery to the fetus. Opioids can result in low birth weight babies, prematurity, and neonatal abstinence syndrome (NAS) [11,12].

There is reported decreased executive functioning in children exposed to high levels of alcohol prenatally [5]. It is noted that the intrauterine effects of marijuana and alcohol on the executive functioning of children linger into a minimum of adolescence; therefore, it is reasoned, mothers should refrain from legal substances of abuse, too.

Behavioral resilience after intrauterine substance exposure was explored by [14]. It is reported caregiver supervision in early adolescence, lower exposure to violence in childhood, and lack of intrauterine tobacco exposure predicted behavioral resilience. Exposure to violence affects the normal stress response by the HPA axis. These observations have public health implications for future generations.

\section{Discussion}

The effects of SUD on the fetus are well known and continue to be studied. There is, however, a dearth of information on the pregnant adolescent with SUD, how best to identify young women at risk of SUD and pregnancy, and to help those already affected.

Factors thatinfluencepositiveadaptation inat-riskadolescents, and those who are already involved in substance use and/or are pregnant, need to be further studied. The intergenerational and social ramifications warrant problem solving that is less linear, and more holistic. Fostering resilience requires strength and risk appraisal in this population, amelioration of changeable risk factors, and enhancement of protective factors. These protective factors can be personal qualities or assets, or external supports.

Richardson [2] describes resilience as the ability to grow or adapt to circumstances (Figure 1). People seek adaptation-a state of biopsychospiritual homeostasis. This requires energy for reintegration and growth. Stressors, adversity, and life events interface with protective factors (internal and external) to influence ones response to events. Life disruptions may be planned or unplanned. New life circumstances disrupt homeostasis that require energy to adapt and reintegrate. Interpersonal growth occurs when a person successfully resolves a disruption. In adolescence, there are many more disruptions. The newness of these disruptions, with less coping skills and experience, makes adolescence difficult and can decrease chances for successful outcomes. 


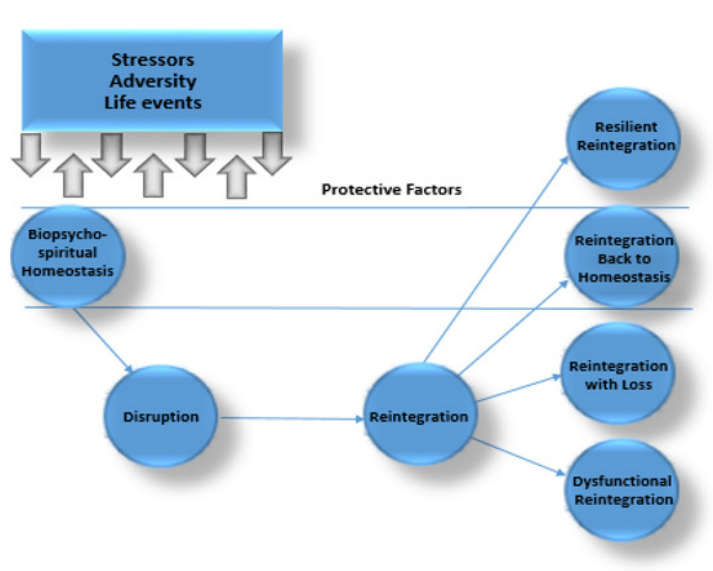

The Resiliency Model (Richardson, 2002)

Figure 1: The Resiliency Model: Metatheory of Resilience and Resiliency.

Many of the stressors of adolescence (physical and hormonal changes, coming to grips with ones sexuality, academic pressures, career/job choices, and learning new skills and responsibilities to transition to the adult role) are normal aspects of this life phase. Educating the student about life changes in health class, and provision of emotional support, are conventional approaches. Teacher awareness of at risk children is a step toward prevention. The stress of impending motherhood may be addressed in special childrearing classes, and childcare for adolescent mothers can help keep them in school. Adolescents at risk need referral to a social worker if exposed to violence, are pregnant, or abusing substances.

When addressing the Resiliency Model, protective factors include personal qualities of higher self- esteem and goaldirectedness. Encouraging and helping students to set goals and celebrating their successes foster both. External supports that serve a protective function can include friends and family. A cautionary point should be that some peers and family might engage in SUD themselves; we must identify the most positive influences possible. Prevention outreach, intervention programs, and interventions are especially useful for younger women, below the poverty level $[2,15]$. The media is especially influential as a "super-peer" to adolescents, shaping normative beliefs; it has been found that substance use among adolescents may be overestimated/ overrepresented in the media, and it may be easier for adolescents to take risks with alcohol and tobacco if they perceive that others engage $[7,15,16]$. Other possible supports to bolster protective factors include increased social work involvement and public health initiatives, especially in impoverished neighborhoods with high exposure to violence. Grants, foundations and programs such as Big Sisters are other sources of support $[17,18]$.

\section{Conclusion}

Richardson's model provides a holistic approach to caring for adolescents at risk for stress, pregnancy and SUD. Fostering resilience involves personal appraisal and improving protective factors for this at-risk population. The pregnant adolescent population sees significant stress in all three realms with SUD, a potential contributing factor to pregnancy. Adaptive response to stress benefits both mother and child. Resilience theory asserts there is opportunity for improving interpersonal growth for dealing with life disruptions. Practitioners and the health care team should focus on the pregnant adolescent as a whole, which includes all disease processes and disorders including substance use disorders. The health care team and practitioners for this population should have access to support both socially and organizationally for the pregnancy and SUD to ensure promotion of healthier maternal and infant outcomes. Continued research focusing on holistic interventions that foster resilience will broaden the understanding for those working with this at-risk population.

\section{References}

1. Palm S, Nylander I (2014) Dopamine Release Dynamics Change during Adolescence and after Voluntary Alcohol Intake. PLoS ONE 9(5): e96337.

2. Richardson GE (2002) The metatheory of resilience and resiliency. Journal of Clinical Psychology, 58(3): 307-321.

3. Green KM, Musci RJ, Matson PA, Johnson RM, Reboussin BA (2017) Developmental Patterns of Adolescent Marijuana and Alcohol Use and Their Joint Association with Sexual Risk Behavior and Outcomes in Young Adulthood. J Urban Health 94(1): 115-124.

4. Panova OV, Kulilov AM, Berchtold A, Suris JC, Panova OV (2016) Factors Associated with Unwanted Pregnancy among Adolescents in Russia. J Pediatr Adolesc Gynecol 29(5): 501-505

5. Frank DA, Rose-Jacobs R, Crooks D, Cabral HJ, Gerteis J, et al. (2011) Adolescent initiation of licit and illicit substance use: Impact of intrauterine exposures and post-natal exposure to violence. Neurotoxicol Teratol 33(1): 100-109.

6. De Genna NM, Cornelius MD, Donovan (2009) Risk factors for young adult substanceuse among women who were teenage mothers. Addict Behav 34(5): 463-470.

7. Mason WA, January SA, Chmelka MB, Parra GR, Savolainen J, et al. (2016) Cumulative contextual risk at birth in relation to adolescent substance use, conduct problems, and risky sex: General and specific predictive associations in a Finnish birth cohort. Addict Behav. 58:161-166.

8. Chaplin TM, Visconti KJ, Molfese PJ, Susman EJ, Klein LC, et al. (2014) Prenatal cocaine exposure differentially affects stress responses in girls and boys: associations with future substance use. Dev Psychopathol 27(1): 163-180.

9. Messiah SE, Lipshultz SE, Miller TL, Accornero VH, Bandstra ES (2012) Assessing latent effects of prenatal cocaine exposure on growth and risk of cardiometabolic disease in late adolescence: design and methods. Int J Pediatr 2012: 467918

10. Lambert BL, Bauer CR (2012) Developmental and behavioral consequences of prenatal cocaine exposure: a review. J Perinatol 32(11): 819-828.

11. Committee on Obstetric Practice (2017) Committee Opinion No. 711: Opioid Use and Opioid Use Disorder in Pregnancy. Journal Obstetrics \& gynecology 130(2): 488-489.

12. Committee on Obstetric Practice (2017) Committee Opinion No. 711: Opioid Use and Opioid Use Disorder in Pregnancy. Obstet Gyne 130(2): e81-e94. 
13. Sithisarn T, Granger DT, Bada HS (2012) Consequences of prenatal substance use. Int J Adolesc Med Health 24(2): 105-112.

14. Liebschutz JM, Crooks D, Rose-Jacobs R, Cabral HJ, Heeren TC, et al. (2015) Prenatal substance exposure: What predicts behavioral resilience by early adolescence?. Psychology of Addictive Behaviors 29(2): 329-337.

15. Smith K, Lipari R (2017) Women of Childbearing Age and Opioids. The CBHSQ Report. Rockville (MD): Substance Abuse and Mental Health Services Administration (US).
16. Elmore KC, Scull TM, Kupersmidt JB (2017) Media as a "Super Peer": How Adolescents Interpret Media Messages Predicts Their Perception of Alcohol and Tobacco Use Norms. J Youth Adolesc 46(2): 376-387.

17. Rose-Jacobs R, Soenksen S, Appugliese DP, Cabral HJ, Richardson MA et al. (2011) Early adolescent executive functioning, intrauterine exposures and own drug use. Neurotoxicol Teratol 33(3): 379-392.

18. Sithisarn T, Granger D, Bada H (2011) Consequences of prenatal substance use. International Journal of Adolescent Medicine and Health 24(2): 105-112.

\section{Your next submission with Juniper Publishers will reach you the below assets}

- Quality Editorial service

- Swift Peer Review

- Reprints availability

- E-prints Service

- Manuscript Podcast for convenient understanding

- Global attainment for your research

- Manuscript accessibility in different formats

( Pdf, E-pub, Full Text, Audio)

- Unceasing customer service

Track the below URL for one-step submission https://juniperpublishers.com/online-submission.php 